\title{
ANATOMY AND PHYSIOLOGY OF DIARTHRODIAL JOINTS
}

\author{
BY
}

\author{
D. V. DAVIES
}

\section{School of Anatomy, Cambridge}

It is proposed to deal only with the freely moving diarthrodial joint with a synovial cavity, omitting many points of interest about the gross anatomy and the mechanics of joints.

The several components of the diarthrodial joint are derived from mesoderm. The joint cavity is developed by liquefaction of the mesenchymal tissue which at first separates the chondrified skeletal elements. The perichondrium (later periosteum) is continued over this cavity as the capsule, while the lining of the cavity presents, on the ends of the bones, the articular cartilage and, on the capsule, the synovial membrane. In some cases, such as the knee and temporo-mandibular joint, liquefaction occurs in two regions in close proximity, the intervening mesenchyme forming the joint disk or meniscus. The capsule, like the periosteum or perichondrium, is composed of tough, inelastic, white fibrous tissue with marked powers of resistance to disease and relatively low powers of repair. The synovial membrane, on the other hand, is a thin, soft, freely movable, elastic membrane, richly supplied with pain fibres, with an abundant blood supply, good powers of repair and well-marked phagocytic properties.

\section{Articular Cartilage}

The articular cartilage is admirably adapted to its purpose. It is so smooth that when lubricated with synovia the friction between the surfaces is reduced to a minimum; it is so elastic that it prevents any jarring of the bones upon one another. It is devoid of sensation so that the movements of the joint, during which the cartilages are subjected to a good deal of pressure by the contraction of muscle and the tension of the ligaments, take place without pain. Finally, it is avascular. "Throughout the life cycle cartilage lives, grows, and decays without a blood supply, without a demonstrable nerve supply" (Harris, 1933). Subjacent to the articular cartilage and separating it from the underlying vascular bone is a zone of calcified cartilage. This increases in depth with age. The articular cartilage when traced towards the joint cavity shows a series of graduated senescent changes likened by Harris (1933) to those seen in the epidermis. Bordering on the calcified cartilage is a zone of proliferation where the cells are frequently arranged in groups of twos and fours, though cells in the act of division are rarely seen. In young bone this zone is continuous at the articular margins with the zone of proliferating cartilage in the epiphyseal disk, these together constituting the mitotic annulus of Harris (1933) (Fig. 1).

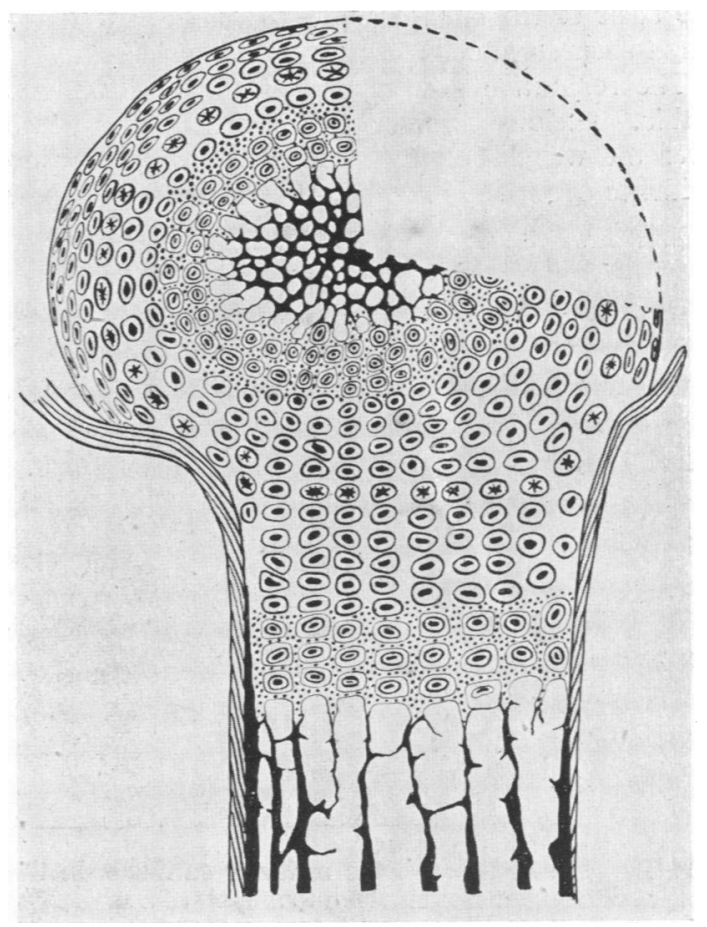

FIG. 1.-Diagram showing the zone of mitoses in articular and epiphyseal cartilages. The cells in this zone have their nuclei shown in the form of asters. (Harris: Bone Growth in Health and Disease, 1933, Fig. 121.)

In the immature animal the normal mechanism of division in the articular cartilage is by mitosis, possibly giving way with age to amitotic division (Elliott, 1936). When traced towards the articular surface the cells derived from this zone of proliferation become flattened and arranged tangentially, gradually losing their staining reaction and shrinking. They reach the articular surface as a sheet of senescent and dead cells to be removed by the constant wear and tear which accompanies joint movements. This senescence and death of cartilage cells has been disregarded in all studies concerning 
the metabolism of articular cartilage. The cell content of articular cartilage decreases with age while the proportion of matrix is correspondingly increased. Rosenthal and his colleagues (1941) estimate that the cell content of bovine articular cartilage decreases by two-thirds from youth to adolescence and by three-quarters from youth to old age.

Even in its deepest layers the metabolic requirements of articular cartilage can be met from substances in the synovial fluid. The respiratory rate of articular cartilage per unit of weight is low as compared with other tissues. The high proportion of matrix accounts for this, so that the glycolytic power per cell is said to be the same as that of other tissues (Bywaters, 1937). The metabolic activity of the cartilage cell is further said to decrease appreciably with age, according to Rosenthal and his colleagues (1941) by $60 \%$ from young to adult in cattle. Whether this is explicable on the basis of the changing proportions of proliferating to senescent cells has not been considered.

The reparative powers of articular cartilage are feeble. Lesions confined to the articular cartilage over the weight-bearing surfaces show little or no evidence of repair. At the articular margins repair

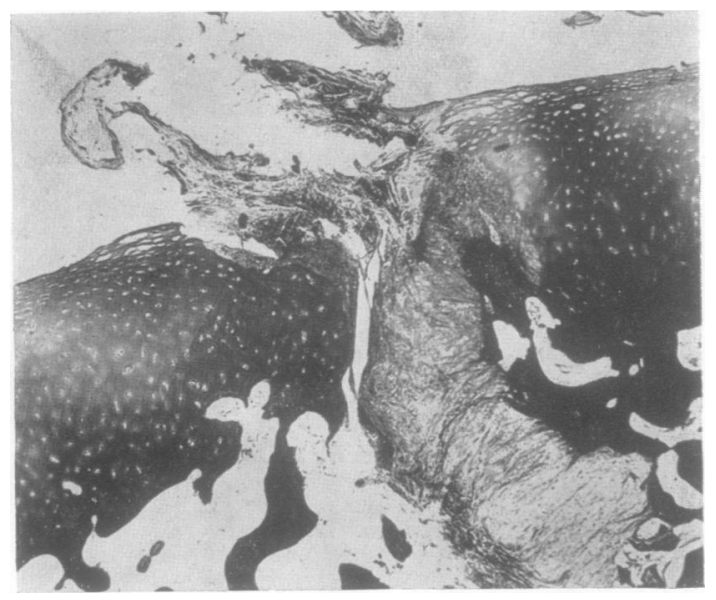

FIG. 2.-Section through the articular cartilage on the head of the radius showing the repair of a six weeks' old fracture. The proliferation of the connective tissue from the marrow spaces to fill the defect in the articular cartilage is seen. $\times 41$.

may be effected by the ingrowth of synovial tissue, which may become transformed into an imperfect fibrous cartilage. Lesions extending through the articular cartilage into the underlying vascular bone and marrow spaces are repaired by proliferation of the connective tissue from the latter, the deeper layers of which may ossify while the most superficial layers may yield a mixture of fibrous tissue and fibrocartilage at the articular surface (Graville et al., 1932; Fisher, 1923). This is also the response in fractures involving articular surfaces (Fig. 2).

Apposition of articular surfaces is essential for the preservation of the normal structure and function of the articular cartilage. Loss of apposition

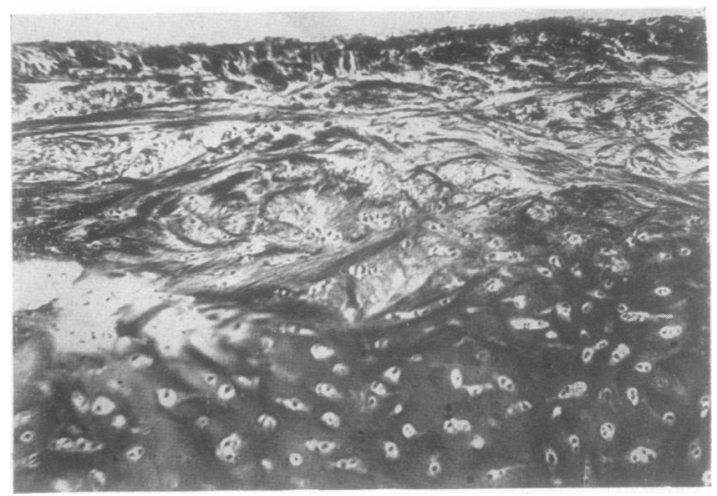

FIG. 3.-Section of the detached fragment from a typical case of osteochondritis dissecans, showing the transformation of the articular cartilage into fibrous tissue. $\times 66$.

leads to a degeneration of the cartilage and its transformation into fibrous tissue. Such a transformation into fibrous tissue is seen in the acetabulum in cases of congenital dislocation of the hip, and in the cartilage covering loose bodies detached from the articular surfaces, as in osteochondritis dissecans (Fig. 3).

Articular cartilage possesses considerable resistance to autolysis both in vivo and in vitro. It also resists the action of various enzymes and toxins which occur in normal and abnormal synovial fluids.

\section{Intra-articular disks}

There has been much speculation in the past as to the morphological and functional value of intraarticular disks or menisci. The constancy of their occurrence and distribution in the mammals is worthy of note. A washer-like action, minimizing the incongruity at the joint surfaces, is hardly justified by their distribution. They are found in the temporo-mandibular joints of practically all mammals, irrespective of the configuration of the joint surfaces. They are even present in the carnivores, in which the articular surfaces are transverse concentric cylinders, accurately adapted one to the other and allowing uni-axial movement. A buffer or shock-absorbing function fails to receive support from their distribution. MacConaill (1932) supposes that they act in the nature of Michel pads, helping to maintain a film of lubricant between the articular surfaces. In most positions of the joint they maintain rather than decrease the incongruity between the articular surfaces, thus creating a wedgeshaped interval, pointing in the direction of motion, through which synovial fluid is continuously fed on to the articulating surfaces.

Structurally they consist not of pure fibrocartilage but of a mixture of cartilage embedded in a much larger mass of dense fibrous tissue. Their removal is said to be followed by a regeneration of fibrous pads from the synovial membrane (Bruce and Walmsley, 1937). Whether this regeneration constantly occurs in all animals and irrespective of age remains unsettled. 


\section{Synovial Membrane}

The synovial membrane covers all the joint surfaces except the cartilage-covered weight-bearing areas. It affords an investment to any tendons or ligaments passing through the joint, covers the edges of the articular cartilage, with which it is firmly adherent, and terminates gradually by shading off into the superficial layer of the cartilage without sharp demarcation. Normally it is very thin and its internal surface is furnished with a variable number of delicate villi and folds, such as the alar folds in the knee-joint, and at the articular margin delicate, frequently overlapping, vascular fringes (Figs. 7 and 8). Occasional cord-like bridges are seen at its reflections from bone to capsule.

The surface of the membrane is relatively cellular,

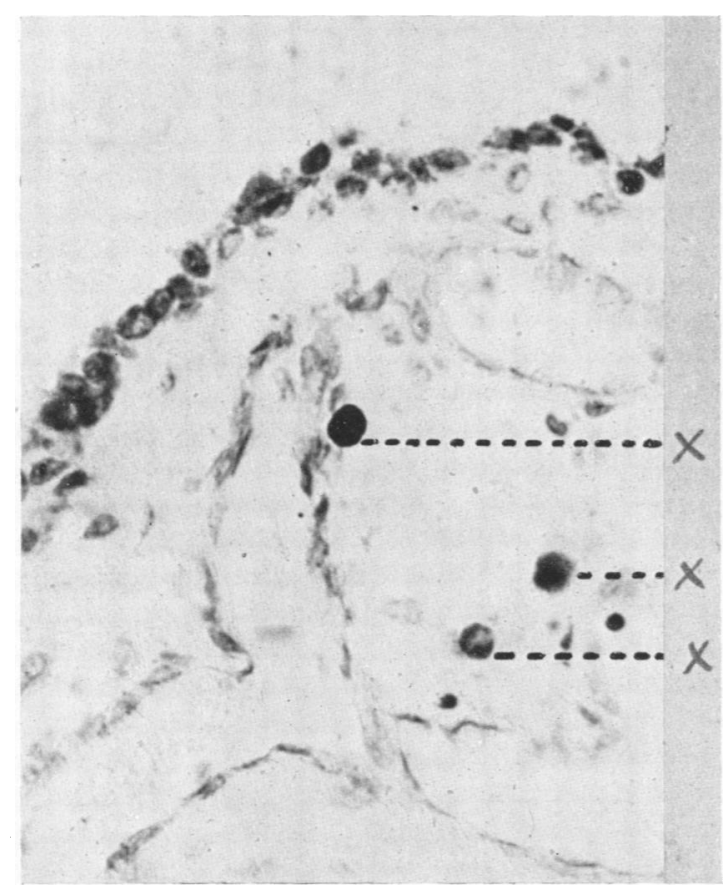

FIG. 4.-Section of the synovial membrane from the ankle-joint of an ox to show the perivascular distribution of the metachromatically stained cells (x). Stained with polychrome methylene blue. $\times 375$.

some portions being richer in cells than others. The cells vary much in size and are generally irregularly branched, the surface of the membrane between the cells, and sometimes over them, being formed by a homogeneous eosinophilic ground substance or by collagenous fibres. No cells with the morphological characters and staining reactions of goblet cells are seen in the synovial membrane. Cèlls staining metachromatically with toluidine blue or thionin do occur in the deeper layers. These have been characterized as mucin-secreting but must be considered as mast cells on account of their characters and perivascular distribution. They are never seen actually at the synovial surface (Davies, 1943) (Fig. 4).

Velpeau (quoted by Todd, 1836), and more recently Key (1928), ascribed much importance to the connective tissue underlying the synovial membrane. Its quantity and quality determines the mobility of the synovial membrane. At the articular margins and lining the ligaments it consists of dense collagenous tissue, restricting independent mobility of the synovial membrane. Elsewhere the underlying tissue is of a loose areolar texture, allowing free movement of the synovial membrane. In most joints there are localized accumulations of fat in various regions in this tissue forming distinct pads, erroneously regarded by Clopton Havers (Todd, 1836) as mucilaginous glands. They fill up the spaces between the bones and between the bones and ligaments in the movements of the joints. According to MacConaill

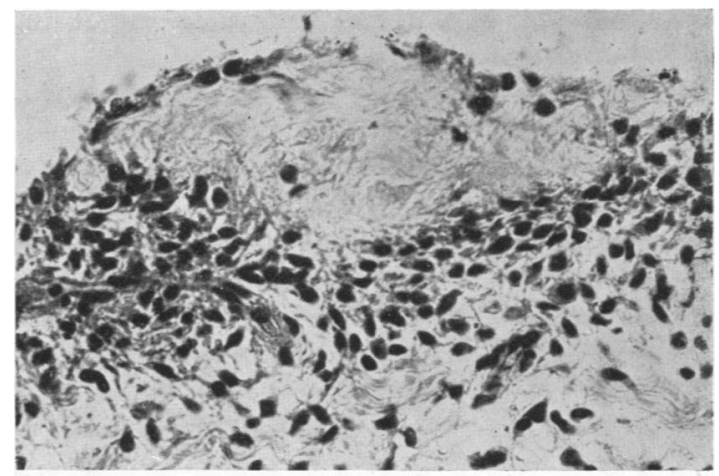

FIG. 5.-Section of the synovial membrane from a human knee-joint, showing the incorporation into the membrane of a deposit of fibrin from the joint. $\times 300$.

(1932) they affect the distribution of the synovial fluid within the joint. The more mobile areas of synovial membrane are provided with an abundance of elastic fibres, often forming one or more distinct elastic laminae. This prevents the membrane being nipped between the articular surface during movement. Villi are devoid of elastic fibres except those in association with the blood vessels. Elastic fibres are sparse where the synovial membrane is firmly adherent to the underlying tissues (Davies, 1946b).

The extent of the synovial membrane in the various joints, and its relation to the area of articular cartilage, is clearly important in connexion with the nutritive functions of the joint. Despite this, comparative figures are not available. Isolated estimates show that whereas in the human knee-joint the area of the synovial membrane is almost double that of the cartilage, in the ankle the proportion is nearer unity (Davies, 1946b).

Much confusion exists as to the nature of the synovial lining. A distinction is frequently drawn between the synovial membrane and the lining of other serous cavities, such as the pleura or peritoneum. Recently the synovial lining has been defined as modified connective tissue. There is little morphological resemblance between the flattened connective tissue lining of false joints and the 
lining layer of true joints (Davies, 1946b). The cells lining the synovial membrane differ from fibroblasts on culture in their ability to lyse fibrin and to secrete a mucin-like substance (Vaubel, 1933a and b). Nor is there much morphological resemblance between the lining of the synovial membrane and that of serous cavities like the pleura or peritoneum. Both, however, exhibit similar reactions to irritation. Key (1928) claims that, following synoviectomy, the lining is reformed by metaplasia of the underlying connective tissue, but there is nothing to show that the newly formed lining preserves the peculiar characters of synovial cells or that the fluid within the joint is not modified by this procedure. In contrast with this is the process of incorporation of fibrin deposits into the synovial membrane by an overgrowth of synovial cells from the periphery of such a deposit, and its subsequent organization (Fig. 5).

\section{Blood Supply and Lymphatic Drainage}

The joint, like the periosteum, is supplied by numerous freely anastomosing blood vessels from the main arteries in the neighbourhood. Free

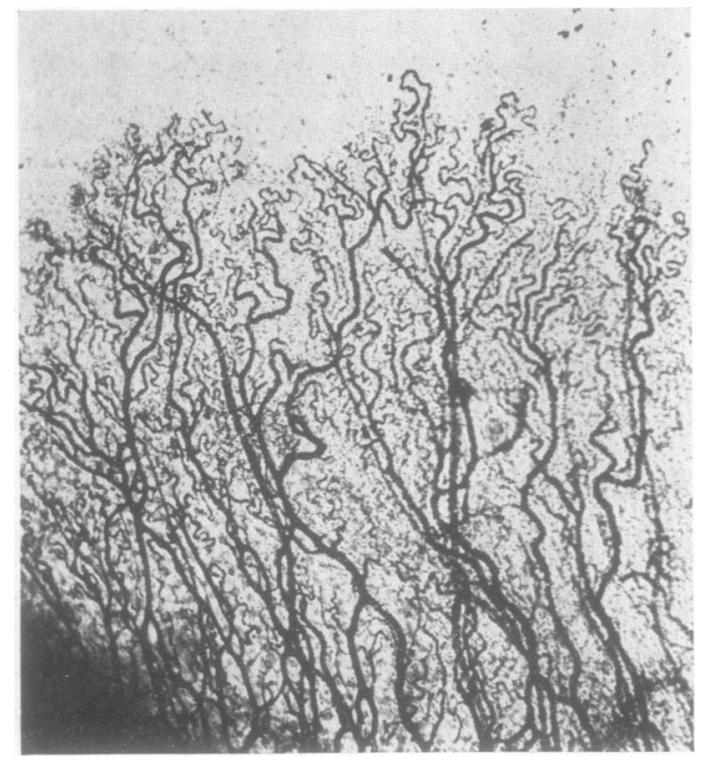

FIG. 6.-Photograph of a cleared specimen of synovial membrane and articular cartilage from the metacarpo-phalangeal joint of an ox, showing the vascular loops at the articular margin. The blood vessels have been injected with India ink. $\times 27 \frac{1}{2}$.

communication exists between the articular blood vessels and those of the adjoining epiphyses. In the synovial membrane the capillaries form a finely meshed network so close to the joint surface that some observers have thought that some of the capillaries may be naked at this surface. The blood vessels advance a short distance upon the nonweight-bearing regions of the articular cartilage, forming the looped anastomoses of the circulus articuli vasculosus of William Hunter (1743) (Fig. 6). In the villi and fringes they form delicate tufts sup-

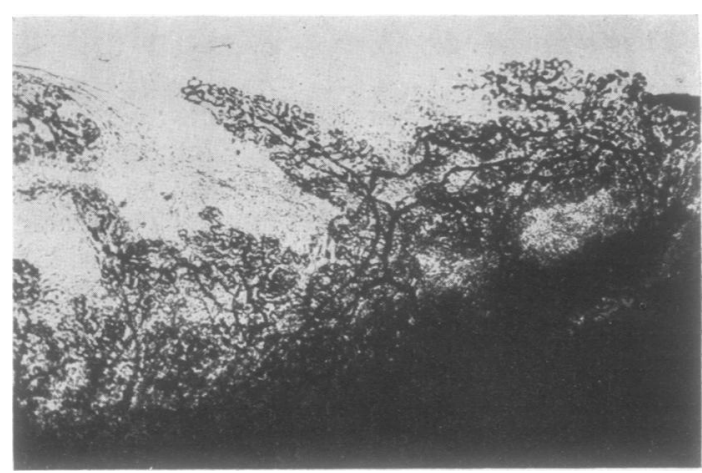

FIG. 7.-Photograph of the synovial folds and fringes from the metacarpo-phalangeal joint of an ox. The blood vessels have been injected with India ink and the specimen cleared. $\times 22$.

plied by one or more central arterioles (Figs. 7 and 8). The richness and superficial position of the synovial capillaries account for the frequency of haemorrhages into the synovial cavity. Simple puncture is almost invariably followed by some extravasation of red blood cells into the synovial fluid, while small extravasations of red cells, not recognizable clinically, accompany almost all traumatic lesions in the vicinity of the joint. Simple bruising over a joint is frequently associated with some extravasation of blood into the fluid. No comparison of the blood supply of joint tissues per gramme per minute with that of other tissues and

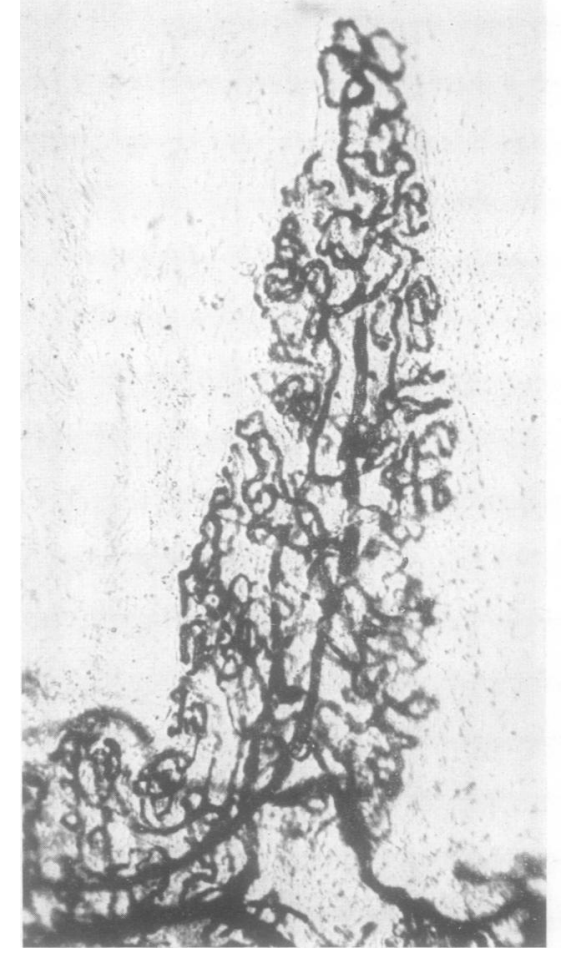

FIG. 8.-High-power view of one of the fringes from the preceding specimen. $\times 84$. 
organs is available. The early liberation of nitrogen into the joint in decompression sickness suggests that the capillaries are near the surface and permeable.

The lymphatic vessels of the synovial membrane are neither as numerous nor as superficial as the blood vessels. Unlike other serous cavities it has generally been considered that no direct communication exists between the cavity of the joint and the lumen of its lymphatics. A single widely-meshed lymphatic plexus lies in the synovial membrane. Within the meshes are numerous blindly ending vessels often exhibiting terminal lacuniform enlarge-

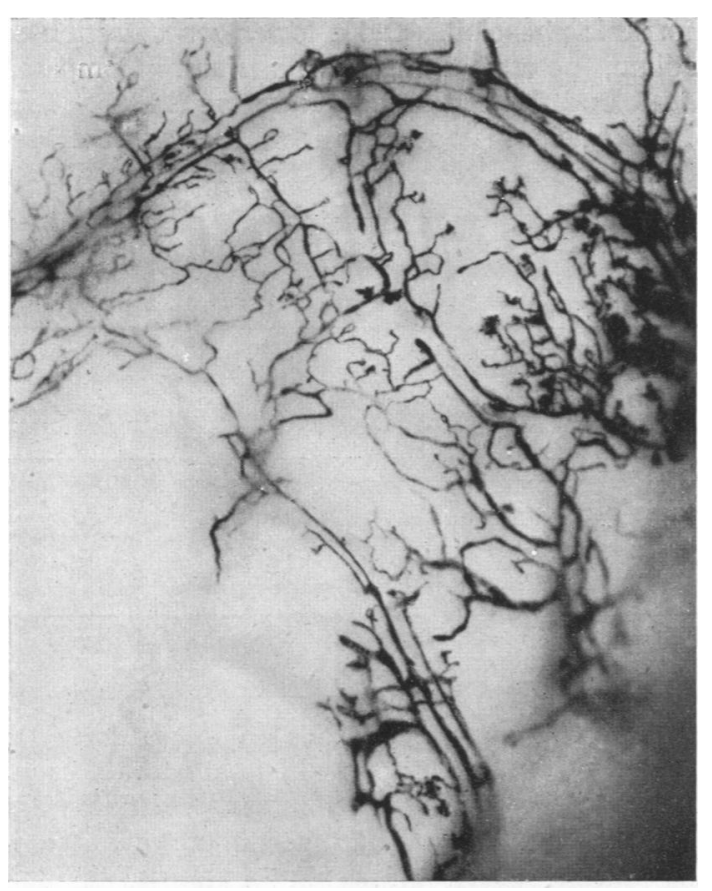

FIG. 9.-Cleared specimen of the synovial membrane from the metatarso-phalangeal joint of an ox, showing the lymphatic vessels. The lymphatics have been injected with India ink. $\times 10$.

ments directed towards the surface of the membrane. From this plexus the main vessels pass in groups of twos and threes along the blood vessels towards the flexor aspect of the limb, and communicate freely with the lymphatic plexus on the periosteum (Fig. 9). Few valves occur in the synovial lymphatics but these are frequent in the periosteal vessels (Davies, 1946a).

\section{Synovial Membrane Nerve Supply}

The nerves to the synovial membrane, both medullated and non-medullated, are partly destined for the blood vessels and for the most part accompany them in their course. The vasomotor nerves, presumably of sympathetic origin, continue along the blood vessels. Many of the remainder terminate as free nerve endings in the more superficial parts of the membrane. These presumably subserve pain sensations to which the synovial membrane is markedly susceptible. Other nerve endings, variously described as of the Ruffini, Golgi-Mazzoni, looped or knotted type, are possibly concerned with sensations such as tension, pressure, or proprioception. Gardner (1942) states that in the mouse the encapsulated nerve endings in the synovial membrane show a distribution which would indicate that they may be stimulated by pressure produced by flexion of the joint. Little is known concerning the extent to which the synovial membrane responds to such stimuli. In an isolated case where the synovial membrane of the knee-joint was exposed and opened under local anaesthesia no evidence of any sensation of pressure touch was found in the synovial membrane away from the area of the infiltration and incision. Tension applied from the edge of the incision of the membrane was appreciated, but its localization was particularly inaccurate. Sensitivity to pain was tested by a sharp needle. This sensation was acute but its localization again failed to be very accurate, except that the side of the joint stimulated was always appreciated correctly.

The physiological co-ordination which exists between the joint and the overlying tissues is summed up in Hilton's Law (John Hilton, 1863). "The same trunks of nerves whose branches supply the groups of muscles moving a joint also furnish a distribution of nerves to the skin over the insertions of the same muscles and-what at this moment more especially merits our attention-the interior of the joint receives its nerves from the same source."

\section{Exchange of Substances across the Synovial Barrier}

Solutions and particles of small molecular dimensions pass rapidly in either direction across the synovial barrier, mainly through the blood capillary bed. The lymphatic system plays a minor part in their absorption; the role of the synovial membrane in this process is probably purely passive though there are some anomalies as yet unexplained by the known laws of osmosis and diffusion. Colloidal particles, including proteins, reach the joint more slowly and their removal is proportionately slow. The synovial cells and phagocytes play an important

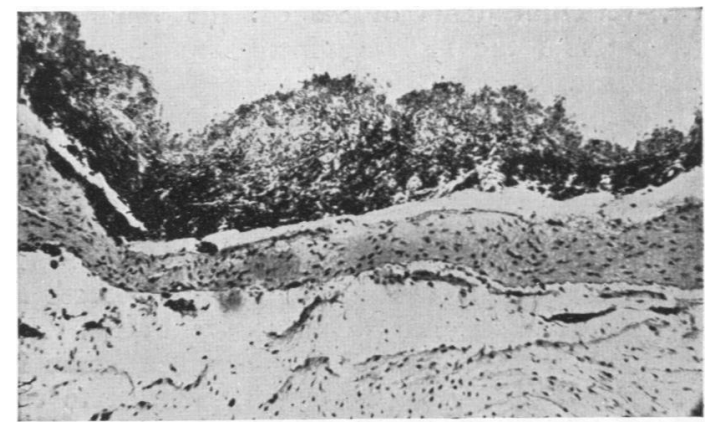

FIG. 10.-Section of the synovial membrane from a human knee-joint, to show the accumulation of haemosiderin. The joint contained a single osteocartilaginous loose body. $\times 55$. 
part in their transfer across the synovial barrier. Particulate matter of $100 \mu$ upwards passes slowly into the subsynovial tissues and is deposited there. Haemosiderin collects there in large quantities following haemorrhage into the joint cavity (Fig. 10). In the removal of particulate matter from the joint the synovial cells and phagocytes of the synovial membrane play an important part. Movement affects the rate of absorption, particularly of small colloidal material. Its effect on the rate of absorption of solutions is less noticeable on account of their very rapid removal even when the joint is immobilized (Adkins and Davies, 1940). Acute inflammation increases the rate of exchange across the synovial barrier; the effects of chronic inflammation seem variable.

Investigations of the absorption from the joint cavity have been mainly confined to animals and, almost without exception, to the knee-joint. It is possible that the rate of transference across the synovial barrier differs from joint to joint in the same animal.

\section{Synovial Fluid}

The synovial fluid differs in its physical, chemical, and cytological characters from joint to joint. The synovial fluid is a viscid, yellowish or colourless, glairy fluid. Its physical characters vary from animal to animal and from joint to joint in the same animal. Its volume bears no close relation to the size or capacity of the joint, though it is moderately constant for any particular joint. The human kneejoint generally contains a small volume $(0.2$ to $0.3 \mathrm{c.cm}$.) of pale straw-coloured fluid, while the smaller knee-joint of sheep or dog contains an equal volume of highly viscous colourless fluid. In the ox the knee-joint contains about $10 \mathrm{c} . \mathrm{cm}$. of fluid, while the smaller ankle-joint has on an average $25 \mathrm{c.cm}$., and sometimes considerably more. In the ankle of the ox the fluid is pale yellow and has a relative viscosity of about 5 at $20^{\circ} \mathrm{C}$., while in the atlanto-occipital or atlanto-axial joints of the same animal the fluid is generally of a deep yellow colour and sets to a gel at $20^{\circ} \mathrm{C}$. In any particular joint there is no constant relation between the volume and the viscosity of the fluid. Serial changes in its physical characters are seen in the costo-vertebral joints of the ox, the volume decreasing and the viscosity increasing on passing backwards (Davies, 1944).

Knowledge of the composition of the synovial fluid is essential to the understanding of its nature. The most reliable and complete analyses are provided by Bauer and his colleagues (1940); - all previous examinations have been fragmentary. Of the blood proteins, albumin and globulin occur in the fluid in considerably lower concentration than in the serum, with a preponderance of albumin in the proportion of about $4: 1$, in contrast to the $1: 1$ ratio found in the serum. There is no fibronogen in the synovial fluid, hence it does not clot on standing, but the mucin may be precipitated in a sac-like fashion, presumably due to $p \mathrm{H}$ changes.
Non-electrolytes-urea, uric and amino acidsare in approximately the same concentration in the synovial fluid as in the serum, suggesting free diffusion of these substances across the barrier of synovial membrane. The concentration of glucose in the fluid is generally less than that in the blood, possibly connected with a consumption of glucose within the joint. Any appreciable increase in the cell content of the synovial fluid is associated with a fall in the glucose content.

The distribution of electrolytes in the synovial fluid is in accord with the Donnan equilibrium theory. There is a higher concentration of chlorides and bicarbonates, a similar concentration of inorganic phosphate, and a lower concentration of sodium, potassium, and magnesium. Compared with blood the calcium concentration is high. Part of this calcium is bound to the mucin and the concentration of calcium in the fluid is proportionate to the mucin content and viscosity (Davies, 1946b). A typical example from an ox is:

\begin{tabular}{l|c|c}
\hline \multicolumn{1}{c|}{ Source of fluid } & $\begin{array}{c}\text { Relative } \\
\text { viscosity } \\
\text { at } 20^{\circ} \text { C. }\end{array}$ & $\begin{array}{c}\text { Calcium in } \\
\text { mgm./100 c.cm. }\end{array}$ \\
\hline $\begin{array}{l}\text { Atlanto-occipital joint } \\
\text { Radio-carpal joint }\end{array}$ & $\begin{array}{l}\text { Set into a gel. } \\
\text { Approximately } \\
2,000 .\end{array}$ & $\begin{array}{c}10.6 \\
7.8\end{array}$ \\
Ankle & 7.9 \\
\hline
\end{tabular}

Any condition causing increased permeability of the synovial membrane leads to increases in the calcium content of the synovial fluid without necessarily yielding parallel increase in the mucin and the viscosity. Such disproportionate increase in the calcium is seen following aspiration of the fluid from the normal joint in the ox. More data concerning the variations in composition of synovial fluid from joint to joint are required.

The viscous polysaccharide of the synovial mucin has recently been isolated by Meyer, Smyth and Dawson (1939). It is a sulphate-free compound termed hyaluronic acid and differs in respect to its sulphate-free nature from the sulphate-containing mucins found in cartilage and gastric secretions (chondritin and mucoitin sulphuric acids). Hyaluronic acid is also found in the viscous components of Wharton's jelly of the umbilical cord, in the vitreous of the eye, and in connective tissue. It is a substance of high-molecular weight, does not dialyse through colloidin membranes, and is nonantigenic. It does not stain metachromatically with such dyes as toluidine blue or thionin, as do the sulphate-containing mucins. Its viscosity is destroyed or decreased by many agents. Among these are vitamin $\mathrm{C}$, which is consequently not found in synovial fluid (Mann, 1940), and an enzyme, hyaluronidase, which is found in testicular extracts and in semen. A similar enzyme is also produced by certain bacteria. 


\section{Cell Content and Cytology}

Observations on the cell content and cytology of normal human synovial fluid are few and confined to the knee-joint. The largest series is that of Coggeshall, Warren, and Bauer (1940), involving 29 observations from a series of 16 cases, ranging from 32 to 80 years of age. The average nucleated cell count was 63 per c.mm. with a range of 13 to 180 cells per c.mm. The fluid was obtained immediately post mortem; the subjects mainly suffered from chronic diseases and had been confined to bed for some time before death. The following limited observations from cases suffering sudden death by accident and having no evidence of articular disease indicate that these values are probably too low for subjects maintaining full use of their joints:

\begin{tabular}{c|c|c|l|c|c}
\hline $\begin{array}{c}\text { Case } \\
\text { No. }\end{array}$ & Sex & Age & Joint & $\begin{array}{c}\text { Nucleated } \\
\text { cells per } \\
\text { c.mm. }\end{array}$ & $\begin{array}{c}\text { Red blood } \\
\text { cells per } \\
\text { c.mm. }\end{array}$ \\
\hline & & & & & \\
1 & M & 25 & Right elbow & 420 & 0 \\
1 & M & 25 & "’ knee & 481 & 186 \\
2 & M & 56 & Left elbow & 234 & 2,000 \\
3 & F & 12 & knee & 286 & 4,000 \\
4 & M & 23 & Right ankle & 80 & 21 \\
4 & M & 23 & Left knee & 152 & 26 \\
4 & M & 23 & Right knee & 146 & 39 \\
\hline
\end{tabular}

In this connexion studies on the cell content of animal synovial fluid reveal several points of interest. The content of nucleated cells varies significantly from joint to joint in the same animal and from species to species. It decreases with age within the species. In cattle, fluids with a high nucleated-cell content were obtained from joints with highly viscous synovia and a marked freedom from diseases and degenerative changes. Thus the nucleatedcell content in the highly viscous fluids in the atlanto-occipital and atlanto-axial joints was of the order of 1,200 per c.mm., while that in the much less viscous ankle-joint fluid was about 200 per c.mm. Functional differences, though obviously influencing the nucleated-cell content markedly, are not adequate to explain all the differences (Davies, 1945a). Marked degenerative changes in a human joint are often associated with raised contents of nucleated cells but not invariably so. Increased wear and tear within the human kneejoint, such as that resulting from torn semilunar cartilages, is associated with a rise in cell content generally, ranging from 300 to 700 per c.mm., rarely exceeding 1,000 per c.mm.

Red cells do not normally occur in synovial fluid though, as already indicated, even simple puncture is followed by some extravasation. Of nucleated cells, monocytes and clasmatocytes preponderate in normal synovial fluid. Lymphocytes are present in small numbers, while only very occasional polymorphonuclear leucocytes are seen. Certain cells designated as synovial cells also occur in small numbers.

\section{Theories of Origin of Synovial Fluid}

The work of Bauer and his colleagues (1940) on the composition of synovial fluid indicates that it is probably an ultrafiltrate, or dialysate, of blood plasma with the addition of mucin. The mucin cannot be a product of the articular cartilage as the two mucins are different. It is not a product of the metachromatically staining cells of the synovial membrane as these are mast cells and sulphate-free mucins do not stain metachromatically. It may arise as a secretion of the synovial cells, a view which is strongly supported by Vaubel's observations (1933a and b) that these cells in tissue culture do secrete a mucin-like substance. The identity of the latter is still awaited. Finally, the mucin may be the matrix of the surrounding connective tissue washed into the joint cavity. In this case the mucin in the joint should be of the sulphate-free and sulphate-containing types, both of which exist in the connective tissue, and should occur in the same proportion as in the connective tissue. There is no evidence that this is the case. Mucin production is probably a slow process. Aspiration of a normal joint in cattle is rapidly followed by restoration of the volume of the fluid but with considerably diminished mucin content and viscosity (Davies, 1946b).

Lubrication of the joint is obviously one of the functions of the synovial fluid. The mucin has high osmotic properties and maintains the fluid in the joint. Further, the mucin may act as a buffer maintaining the alkalinity of the fluid, in association with the calcium. Nutrition of the articular cartilage, particularly in its central portions, is almost exclusively done by the synovial fluid. All other functions must take second place to this.

I wish to thank Professor H. A. Harris for permission to reproduce Fig. 1.

\section{REFERENCES}

Adkins, E. W. O., and Davies, D. V. (1940). Quart. J. exp. Physiol.,

Bauer, W., Ropes, M. W., and Waine, H. (1940). Phys. Rev., 20, 272 .

Bennett, G. A., and Bauer, W. (1932). Amer. J. Path., 8, 499.

Bruce, J., and Walmsley, R. (1937). Brit. J. Surg., 25, 17.

Bywaters, E. G. L. (1937). J. Path. Bact., 44, 247

Coggeshall, H. C., Warren, C. F., and Bauer, W. (1940). Anat. Rec., $77,129$.

Davies, D. V. (1943). J. Anat., 77, 160

(1944). Ibid., 78, 68 .

(1945). Ibid., 79, 66 .

(1946a). Ibid., 89, 21.

(1946b). Lancet, in the Press.

Elliott, H. C. (1936). Amer. J. Anat., 58, 127.

Fisher, A. G. T. (1923). Lancet, 2, 541.

Graville, B. and Bauer, W. (1932) Am. Jour. Path., 7, 499.

Harris, H. A. (1933). Bone Growth in Health and Disease. Oxford University Press. London.

Hilton, J. (1863). Rest and Pain. London.

Key, J. A. (1928). Special Cytology. Edited by E. V. Cowdry, Vol. II, p. 735. New York.

Lutwak-Mann, C. (1940). Biochem. J., 34, 517.

MacConaill, M. A. (1932). J. Anat., 66, 210.

Meyer, K., Smyth, E. M., and Dawson, M. H. (1939). J.biol. Chem., 128, 319.

Rosenthal, O., Bowie, M. A., and Wagoner, G. (1941). J. Cell. Comp. Physiol., 17, 221.

Todd, R. B. (1836). Cyclopaedia of Anatomy \& Physiology, Vol. I. London.

Vaubel, E. (1933a). J. exp. Med., 58, 63.

- (1933b). Ibid., 58, 85 . 